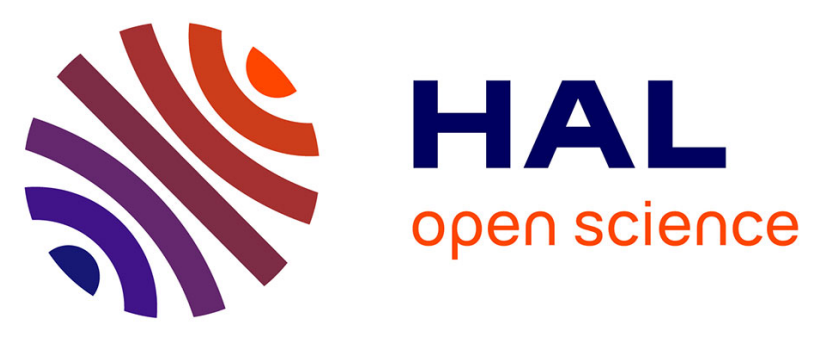

\title{
Impact of lip-reading on speech perception in French-speaking children at risk for reading failure assessed from age 5 to 7
}

Agnès Piquard-Kipffer, Thalia Cavadini, Liliane Sprenger-Charolles, Edouard Gentaz

\section{To cite this version:}

Agnès Piquard-Kipffer, Thalia Cavadini, Liliane Sprenger-Charolles, Edouard Gentaz. Impact of lipreading on speech perception in French-speaking children at risk for reading failure assessed from age 5 to 7. Annee Psychologique, 2021, 121, pp.3-18. 10.3917/anpsy1.212.0003 . hal-03482032

\section{HAL Id: hal-03482032 \\ https://hal.inria.fr/hal-03482032}

Submitted on 15 Dec 2021

HAL is a multi-disciplinary open access archive for the deposit and dissemination of scientific research documents, whether they are published or not. The documents may come from teaching and research institutions in France or abroad, or from public or private research centers.
L'archive ouverte pluridisciplinaire HAL, est destinée au dépôt et à la diffusion de documents scientifiques de niveau recherche, publiés ou non, émanant des établissements d'enseignement et de recherche français ou étrangers, des laboratoires publics ou privés. 


\title{
Impact of lip-reading on speech perception in French-speaking children at risk for reading failure assessed from age 5 to 7
}

\author{
Agnès PIQUARD-KIPFFER ${ }^{1}$, Thalia CAVADINI ${ }^{2}$, Liliane SPRENGER-CHAROLLES ${ }^{3}$ \& \\ Edouard GENTAZ ${ }^{2,3, *}$
}

${ }^{1}$ Université de Lorraine, CNRS, Inria, LORIA, F-54000 Nancy, France

${ }^{2}$ Faculty of Psychology and Educational Sciences, University of Geneva, Switzerland

${ }^{3}$ CNRS, Laboratoire de Psychologie Cognitive, Aix-Marseille University, France

*Corresponding author : Prof. Edouard Gentaz, Faculty of Psychology and Educational Sciences, University of Geneva, 40 boulevard du Pont-d'Arve, 1211 Geneva 4, Switzerland. Email: Edouard.Gentaz@ unige.ch. http://www.unige.ch/fapse/sensori-moteur/index.html 


\title{
Impact of lip-reading on speech perception in French-speaking children at-risk for reading failure assessed from age 5 to 7
}

\begin{abstract}
Using facial gestures (especially lip reading) is known to improve speech comprehension. In the context of the COVID-19 pandemic, most teachers wear masks. This can affect learning to read, especially for children with poor phonemic discrimination skills. In this study, a group of children at risk for reading failure and a not at risk group were assessed from age 5 to 7 . These two groups were formed according to their scores on a phonemic discrimination test at age 5: the "Atrisk group" $(\mathrm{N}=39)$ and the "Not-at-risk group" $(\mathrm{N}=46)$. To test the effect of not being able to rely on lip reading on the phonemic test, a syllabic counting task was given to the same groups of children at age 5 and 7 under two conditions: with the possibility to read lips or without (the stimuli were either pronounced by the experimenter or pre-recorded with no visual component). The results revealed a positive effect of lip-reading condition only for the at-risk group at both ages, with scores which remained similar over time. By contrast, scores for the not-at-risk group increased between the two ages, whatever the lip-reading condition. These results suggest that in the context of the COVID-19 pandemic in which teachers wear masks, this condition may interfere with learning to read for children at risk due to poor phonemic discrimination skills.
\end{abstract}

Keywords: Reading acquisition; Pre-reading skills; Lip reading; Phonemic discrimination; Phonemic segmentation; Syllabic segmentation; Longitudinal design; likely-a-mask condition. 


\section{Impact de la lecture labiale sur la perception de la parole chez des enfants}

\section{francophones "à risque" de devenir mauvais lecteurs évalués à 5 et 7 ans}

\section{RESUMÉ}

Dans une situation de communication, l'apport de l'expression faciale, particulièrement de la lecture labiale, est reconnu comme facilitant la compréhension orale. Dans le contexte de la pandémie liée à la COVID-19, la plupart des enseignants portent un masque. Cela peut affecter l'apprentissage de la lecture, spécialement chez des enfants présentant de faibles capacités de discrimination phonémique. Dans cette étude, deux groupes d'enfants ont été suivis de 5 à 7 ans : un groupe « à risque » de devenir mauvais lecteurs et un groupe «non à risque ». Ces deux groupes ont été constitués selon leurs habiletés à une tâche de discrimination phonémique examinée à l'âge de 5 ans : le groupe "à risque" $(\mathrm{N}=39)$ et le groupe " non à risque" $(\mathrm{N}=46)$. Pour tester l'effet de l'impossibilité de recourir à la lecture labiale dans une épreuve phonologique, une même tâche de comptage syllabique a été proposée aux enfants à 5 ans et à 7 ans avec deux conditions : avec et sans la possibilité d'utiliser la lecture labiale (les stimili étant soient prononcés par l'expérimenteur, soit pré-enregistrés : une condition similaire à celle où le masque est porté). Les résultats montrent un effet positif de la condition avec lecture labiale seulement pour le groupe « à risque », quel que soit l'âge, avec des scores restant similaires dans le temps. A l'inverse, les scores du groupe «non à risque » ont augmenté dans le temps, avec ou sans recours à la lecture labiale. Ces résultats suggèrent que dans le contexte de la pandémie liée à la COVID-19 où les enseignants portent un masque, cette condition peut interférer avec l'apprentissage de la lecture chez des enfants «à risque » par rapport à cet apprentissage en raison d'un déficit de discrimination phonémique. 
Mots-clefs: enfant; lecture; lecture labiale; discrimination phonémique ; segmentation phonémique ; segmentation syllabique; approche longitudinale; condition "quasi-masque” 


\section{INTRODUCTION}

It is well known that seeing a speaker's articulatory mouth gestures, here referred to as lip-reading or visual speech, can help us decode auditory speech signals in everyday situations (Sumby \& Pollack, 1954). Studies have shown when individuals processes visual and audio-visual signals, they mainly use the movements of articulators located in the oral area (lips, jaw, tongue and teeth) to increase intelligibility of the acoustic speech signal (Dodd \& Campbell, 1987). The lip movements can play a significant (but not essential) role because they are intelligible even without an auditory signal, likely because there is a strong connection between auditory and visual speech (Munhall \& Vatikiotis-Bateson, 2004).

There is an old-standing debate in the field of speech communication over whether speech perception involves multisensory representations, in addition to procedural knowledge about speech perception, and its relation to speech production. The most commonly held motor theory of perception (Viviani, 2002) is the one proposed by Liberman \& Mattingly (1985) to account for the effectiveness with which phonemes (a small portion of the speech signal, not linearly perceptible because of co-articulation) are extracted from the acoustic flow. Liberman \& Mattingly argued that the objects of speech perception are the intended phonetic gestures of the speaker represented in the listener's brain as the invariant motor commands that he himself would have issued to produce the same sounds (for the links between the motor theory of speech and reading, see Cole \& Sprenger-Charolles, 2021). According to neurobiological studies (Pulvermüller, Huss, Kherif, et

al. 2006; Studdert-Kennedy, 2005), the perception of speech sounds is the result of a motor simulation of articulatory gestures corresponding to phonetic features. 
If this hypothesis is valid, the principles at work must have become engrained in the perceptual system with equal progress, and in strict association with the development of the specific mechanisms for speech perception, quite independently of any regularity present in nature. Currently, this theoretical question is still under debate in the literature and it is not yet clear how brain encodes information to extract meaning from visual speech. Visual speech may be recoded into acoustic information but this is computationally demanding (Bourguignon, Baart, Kapnoula, \& Molinaro, 2020). Other authors have suggested that meaning is directly extracted from visual speech within visual areas and heteromodal association cortices (Bernstein \& Liebenthal, 2014). According to this view, activation in early auditory cortices driven by lip-reading might reflect imagery of unrelated (possibly speech) sounds, but not a direct recoding of visual speech into its corresponding acoustic representation. There is no empirical evidence to disentangle these alternatives.

In any case, speech perception is auditory-visual both in adults and infants. For instance, infants use visual speech information to facilitate auditory input by one month of age. They match auditory and visual input by three to four months, and integrate auditory and visual information by four months (Sekiyama \& Burnham, 2008). The latter, auditory-visual integration, is often measured using the McGurk effect, in which the auditory /ba/ dubbed onto /ga/ lip movements, is perceived as neither the auditory nor the visual component but as the emergent percept "da" or "ta" (McGurk \& MacDonald, 1976). This emergent percept version of the McGurk effect (Burnham \& Dodd, 2004) is perceived in 5-month old infants. While auditory-visual speech perception is well established in infancy, it continues to develop into early and later childhood. For example, McGurk and MacDonald (1976) found that visual speech influence increased from preschool (ages 3-5) to school (ages 7-8) to adulthood, a developmental trend consistently supported by subsequent studies (Sekiyama \& Burnham, 2008). Thus, despite relatively mature auditory-visual speech perception 
in infancy, the use of visual speech information continues to improve into early childhood and beyond. It should be noted that, unlike some Asian languages such as Chinese or Japanese where the auditory information given by a speaker is central (both for cultural reasons of impoliteness to look at the face of the interlocutor and the phonetic properties of these languages), in French as in English, the contribution of the visual signal is essential for disambiguating close phonetic contrasts (For a review of interlanguage studies on the Mc Gurk effect, see Colin \& Radeau, 2003).

Previous research, however, indicates that preschoolers who make developmentally related speech errors perform differently from controls on lip-reading tasks (Desjardins, Rogers, \& Werker 1997). These findings have been interpreted as evidence that lip-read and heard speech are integrated in an articulatory code. Desjardins et al. (1997) argued that an inability to correctly produce consonants would interfere with the ability to lip-read. Using an original test for the susceptibility to the McGurk effect, they tested preschoolers in two groups, substituters (those who made substitution errors), nonsubstituters (those who did not) as well as adults in an auditory-only condition, a visual-only condition, and an audiovisual condition. No difference among groups in the auditory-only condition was observed. Overall, preschoolers still showed less visual influence than adults. Substituters were poorer at lip-reading in the visual-only condition and showed less visual influence on the incongruent audiovisual tokens than did nonsubstituters. According to these authors, experience correctly producing consonants plays a role in the elaboration of the underlying representation. However, in using the McGurk effect, Dodd, McIntosh, Erdener, \& Burnham, (2008) compared children with delayed and disordered speech on perception of this illusion. Although neither group perceived many illusions, a significant interaction indicated that children with disordered phonology were strongly biased toward the auditory component, while the delayed group's response was more evenly split between the auditory and visual illusion components. These findings suggest that phonological processing, rather than articulation, supports lip-reading ability. 
The development of the use of visual speech information in childhood is related to two other interrelated factors: a second period of perceptual attunement around the onset of reading instruction and the structure of particular languages (both their phonology and their orthography, including the phoneme-grapheme relationship). While visual speech perception abilities are not related to vocabulary in pre-readers, they are put to good use once reading instruction begins; those children who are good at using visual speech information also have sharper perceptual attunement - greater perceptual superiority for native over non-native speech sounds (Erdener \& Burnham 2017). Thus, during this reading acquisition period, attention to visual information may well aid grapheme-to-phoneme mapping, a crucial ability for reading.

Studies have been undertaken in the field of visual speech combined with reading, mostly for young children who are at risk for reading acquisition. Most of these studies have been conducted in the field of deafness, showing that lip reading is positively connected to the development of literacy (Arnold \& Köpsel, 1996; Kyle \& Harris, 2006). Some of these studies put forward the hypothesis that lip reading provides access to the phonological units that are necessary for effective reading (Alegría, Charlier \& Mattys, 1999), more directly than the classical phonological awareness tasks.

The situation created by the Covid-19 crisis in which teachers wear masks - generally nontransparent ones - should have a negative impact on speech perception, and indirectly on reading acquisition. We expected this impact would be greater in children with phonemic discrimination deficits. It is now widely accepted that, at least in alphabetical writing, learning to read depends on children's phonological abilities, especially those at the phonemic level (Bara, Colé \& Gentaz, 2008; Gentaz, Sprenger-Charolles, Theurel \& Colé, 2013). Most studies in this area have focused on phonemic awareness, i.e. the ability to segment speech into phonemes, often evaluated by the deletion of the first consonant in Consonant-Vowel-Consonant (CCV) pseudowords. Without this 
ability, it is difficult to link the basic units of this writing (the graphemes) to the corresponding phonemes (Castles, Rastle \& Nation, 2018), the sine qua non of reading acquisition (Share, 1995; Ziegler, Perry \& Zorzi, 2014). Phonemic segmentation skills are necessary to understand and use the alphabetic principle, but not to speak. However, to learn both speaking and reading, the ability to accurately discriminate words that differ only by one phoneme is crucial, for instance differing only in voicing (/p/-/b/, in "pig" vs. "big"; /t/-/d/, in "tear" vs. "dear") or by the locus of articulation (p/-/t/, in "pick" vs. "tick"; /b/-/d/, in "big" vs. "dig”). Results suggest that phonemic discrimination skills may also be very important for learning to read. In a longitudinal study by Piquard-Kipffer \& Sprenger-Charolles (2013), two groups of French-speaking children were selected based on their phonemic discrimination skills at age 5: A group with low skills and a group with average to high skills in that domain. These two groups were classified as being "at-risk" and "not-at-risk" for reading acquisition, respectively, and were matched on chronological age, nonverbal IQ and vocabulary. These two groups defined at age 5 based on their phonemic discrimination skills obtained significantly different reading scores at age 8: The proportion of children with reading disabilities was higher in the at-risk group than in the not-at-risk group. Among the early predictors of reading acquisition, it is thus crucial to assess the impact of phonemic discrimination, a skill that has very rarely been assessed in longitudinal studies (Snowling, Gooch, McArthur \& Hulme, 2018), and not only phonemic segmentation, as in most previous longitudinal studies.

The aim of the present study was therefore to investigate the effect over time of having or not having access to lip reading on speech perception in children with poor phonemic discrimination skills (at-risk group) compared to a not-at-risk group using an original syllabic counting task with two conditions: re-recorded (without access to lip reading) or live (with access to lip reading). Firstly, we hypothesized that children with phonemic discrimination deficits should globally perform better in syllabic counting when they have access to lip reading. Higher scores 
were also expected in this modality at both measurement times (at age 5 and 7). Moreover, by age 7, children with phonemic discrimination difficulties (at-risk group) should have progressed further in the modality to which they are exposed daily (i.e., the one in which they perceive the speaker's articulatory movements) than in the pre-recorded condition where they could not rely on lip reading to complete the syllabic counting task. In contrast, we secondly hypothesized that the not-at-risk chidren should have significantly higher syllabic counting scores at age 7 than at age 5 regardless of the task format (with or without lip reading access), since we expected a classical learning effect over time in these children.

\section{METHOD}

\subsection{Participants}

The participants were selected among a cohort of children who were native speakers of French and who, at age 4 (Time 0), had normal hearing, normal or corrected-to-normal vision, no history of language impairment (collected from interviews with the family) and who had not had linguistic, motor or psychological therapies. Additional tests (Piquard-Kipffer \& SprengerCharolles, 2013) were carried out at the age of 5 (Time 1a) to assess vocabulary (Deltour \& Hupkens, 1980), nonverbal IQ (Raven, 1996), and pre-reading level (Savigny, 1974). The last test was used to ensure that the children were non-readers, i.e. unable to blend a consonant with a vowel. All children with nonverbal IQ and vocabulary level in the normal range were included in the cohort. Risk was defined on the bases of scores on a phonemic discrimination test (see below for a presentation of the task). The scores of 42 children on this test were under the first quartile (at-risk), those of 83 children were over the median (not-at-risk), and those of 40 children were in between. Children from this last group were not included in the longitudinal cohort. Among the 125 remaining children, we were able to follow up with 85 children until the end of Grade 2 (Time 
3): 39 at-risk children ( 24 boys and 16 girls) and 46 not-at-risk children ( 28 boys and 18 girls). It should be noted that 25 children disappeared from the sample because of a move and we were unable to test 15 children in time, that is, within the limit of a 5-week testing period. Among the 40 children who disappeared, most (37) were from the not-at-risk group. However, between the not-at-risk children who were kept in the cohort and those who disappeared, there were no differences in nonverbal IQ, vocabulary or phonemic discrimination (means and SDs: 18.83 (3.55) vs. 18.68 (3.30); 39.48 (5.55) vs. 39.43 (6.26); 30.72 (2.26) vs. 30.68 (2.10) respectively; all t< 1). The two first test sessions took place in 17 kindergartens, the two others in 26 public primary schools in France.

The main characteristics of the two groups are presented in Table 1, with means, standard deviations and t-tests for independent groups (see below for a presentation of the tasks). At age 5 (Time 1a), there were no significant differences between the two groups in chronological age $(t(83)$ $=1.64, \mathrm{~ns})$, nonverbal IQ $(\mathrm{t}(83)=-1.45, \mathrm{~ns})$ or vocabulary $(\mathrm{t}(83)=-0.04, \mathrm{~ns})$. There was a significant group difference in pre-reading level $(\mathrm{t}(83)=-2.99, \mathrm{p}<.004)$.

(insert Table 1)

The total sample size had to be a minimum of 26 participants per group according to Gpower considering an error of $\mathrm{a}=.05$, a power of .80 , an effect size of .40 (Cohen, 1969), 2 groups and $\mathrm{N}-1$ degrees of freedom as parameters of an a priori analysis computing the required sample size with an ANOVA.

Finally, the present study was conducted in accordance with the Declaration of Helsinki, with the written consent of each child's parent and it was in accordance with the ethics convention 
between the academic organizations (University of Paris and LEAPLE-CNRS) and educational organizations of France.

\subsection{Tasks and procedure}

The complete procedure used to select the two groups of children was presented in Piquard-Kipffer \& Sprenger-Charolles (2013). Children of both groups were seen individually in a quiet room. The impact of the possibility to rely on lip reading was assessed by a syllabic counting test which was taken with two modalities: pre-recorded (without the possibility to rely on lip reading) or live (in a counterbalanced order). The test included 10 pseudowords with a $\mathrm{CV}$ structure: 2 bissyllabic (mazu...), 3 trisyllabic (nijaton...), 3 with 4 syllable-items (vakondinu...) and 2 with 5 syllable-items (gavéchiroula...). Three practice items were delivered and no feedback was given during the session. The task involved a response with a number " $2,3 \ldots$... The total number of correct responses was scored for each child (maximum: 10 for each test). The two conditions of this task were given when they were 5 (middle of kindergarten; T1b) and and again when they were 7 (end of grade 1; T2).

\section{RESULTS}

Firstly, we examined differences (paired sample t-test and Cohen's D) in syllabic counting scores with lip reading and without at each measurement time in the two groups of children. In order to simultaneously evaluate the effect of our two within-subjects factors (time: age 5/age 7 and test modality: with/without lip-reading) on syllabic counting scores, we then performed a twoway repeated measures analysis of variance with data from each group separately. 
Syllabic counting scores with access to lip reading and without for both groups of children at ages 5 and 7 are presented in Table 2. The paired sample t-tests conducted to compare the scores obtained in each test modality at both measurement times showed that in both groups (children with or without a phonemic discrimination deficit, hereinafter at-risk and not-at-risk groups), the difference in syllabic counting scores with lip-reading versus without is significant only at the second measurement time (at age 7) $(t(45)=-2.514, p=.016$ and $t(38)=-2.371, p=.023$ ), indicating that at age 5 the children in both groups have statistically equivalent syllabic counting performance whether they can - or cannot - use lip reading when performing the task $(t(45)=-$ $0.256, p=.799$ and $t(38)=-1.909, p=.064)$.

(insert Table 2)

Although the difference between syllabic counting scores with lip reading versus without was significant only at age 7 in the at-risk group, the repeated measures ANOVA revealed a significant main effect of task modality in this group $(F(1,38)=4.94, p=.032)$. Interestingly, this analysis also showed that neither the main effect of time $(F(1,38)=0.11, p=.736)$ nor the interaction effect were significant $(F(1,38)=0.04, p=.836)$. These results suggest that the progress in syllabic counting for the at-risk group between the ages of 5 and 7 seems to be related to the possibility of using lip reading and not to age. As soon as they can lip read, these children have higher scores at either 5 or 7 years of age, whereas when they do not have access to lip reading, their syllabic counting scores are lower at both ages and remain statistically similar (Figure 1a).

In sharp contrast, in the not-at-risk group, the main effect of age on syllabic counting was significant $(F(1,45)=12.90, p=.001)$, nor was the interaction effect $(F(1,45)=0.96, p=.332)$, while the possibility of lip-reading was not $(F(1,45)=2.46, p=.124)$. Thus, the syllabic counting 
scores of the not-at-risk children were significantly higher at age 7 than at age 5 regardless of lipreading possibility (Figure $1 \mathrm{~b})$.

(insert Figure 1)

Finally, the analyses of correlations (Pearson's r) between scores in syllabic counting with lip reading and without obtained in each condition at age 5 and those obtained at age 7 revealed significant positive correlations between these two test sessions for the at-risk group (with and without lip reading: $\mathrm{r}=.959 ; p<.001$ and $\mathrm{r}=.960 ; p<.001$, respectively). For the not-at-risk group, the correlation was weaker in the lip-reading condition $(\mathrm{r}=.322 ; p<.05)$ and non significant in the not-at-risk group without lip-reading condition $(\mathrm{r}=.150 ; \mathrm{ns})$. This is probably explainable by "a ceiling effect" (with high syllabic counting scores).

\section{DISCUSSION}

The main result revealed a positive effect of the lip reading condition only for the at-risk group at both ages, with scores which remained similar (with also a very good reliability) over time. These results partially confirmed our hypothesis. Thus, the children in the at-risk group may use visual speech information to compensate for their deficit in phonemic discrimination at age 5, and continue to do use it until age 7.

However, contrary to our hypothesis, no progress over time in syllabic counting has been observed in the at-risk group. With the same follow-up study, Piquard-Kipffer \& SprengerCharolles (2013) already showed (at age 5) a significant group difference for phonological shortterm memory (STM, repetition of pseudowords from 3 to 6 syllables) to the benefit of the not-at- 
risk control group, but not for visual STM. In addition, a strong difference was observed between the same groups in a task requiring to pronounce two- or three-syllable pseudowords without their first syllable, that difference being even stronger than the one observed in a task requiring the deletion of the first phoneme of Consonant-Vowel or Consonant-Vowel-Consonant pseudowords. As discussed by Piquard-Kipffer \& Sprenger-Charolles (2013), these results, with those of the regression analyses, suggest that the early skills that most distinguished the groups at age 5 (syllabic segmentation) were not necessarily the most predictive of future reading level at age 8 (e.g., phonemic segmentation; Gentaz, Sprenger-Charolles, Theurel \& Colé 2013; Sprenger-Charolles, Desrochers \& Gentaz, 2018).

In addition, the difference between skills at the phonemic level and, above all, at the syllabic level observed in the study by Piquard-Kipffer \& Sprenger-Charolles (2013), differed from those observed in another study with French-speaking children (Casalis \& Louis-Alexandre, 2000), the stronger difference being to the detriment of the at-risk children in the syllabic segmentation task from the 2013 study. These differences are presumably explained by the experimental procedure: Casalis \& Louis-Alexandre used a syllabic task wherein the experimenter spoke the items out loud; the children therefore benefited from lip-reading cues. In contrast, in the study of Piquard-Kipffer \& Sprenger-Charolles, pseudowords were recorded, thus those cues were not available. These results indicate that it will be important to assess the role of syllabic segmentation with and without the possibility of lip-reading, which was the aim of the present study. These results suggest that visual information brought by the speaker's lips, tongue and other speech organs can facilitate a task that requires both phonological STM and syllabic segmentation skills such as the task of the present study, a syllabic counting task.

By contrast, performances for the not-at-risk group of the present study increase from age 5 to 7 , whatever the lip-reading conditions. Because these children had no phonemic discrimination 
difficulties, and according to the results observed in Piquard-Kipffer \& Sprenger-Charolles (2013), their phonological STM was solid. they did not need to use lip-reading. Therefore, the phonological STM and phonemic discrimination skills of these children are closely connected to their reading achievement which in turn strengthens these abilities.

These results suggest that these children did not need this matching between visual and auditory representations as their phonological STM was solid and they had no phonemic discrimination difficulties. Conversely, the not-at-risk control group results suggest that both their phonemic and syllabic analysis abilities and their phonological STM are closely connected to their reading achievement which in turn strengthens these abilities.

Finally, these results suggest the existence of two types of representations involved in speech perception in French-speaking children which would depend on the reading level and on the phonemic discrimination ability. For the children in the at-risk group, the task can be performed more efficiently with the help of motor knowledge. In other words, with faces with incomplete information, the perceptual system fills the gap by drawing from motor knowledge. For these children, the speech information may recode into a multisensory representation using motor knowledge. More generally, motor knowledge concerns the characteristics, properties and constraints of bodily movements taken into account by the process that turns sensory inputs related to dynamic events into perceptual representations (Viviani, 2002). Thus, the perception of dynamic events arises from the interplay between the sensory data and the principles and constraints exhibited in our embodied competence. By contrast, for the not-at-risk children, the speech information may be recoded into an acoustic or abstract representation in which the visual information and motor knowledge would be not significant. It is to be underlined that the children included in the study were all non-readers, i.e. unable to blend a consonant with a vowel on the task used to assess their pre-reading skills. Thus, the observation of group differences in the reading 
of the five vowels included in that task highlights the importance of assessing vowel processing in pre-reading tests. These findings contrast with those observed in English (McBride-Chang, 1999). They may be explained by two main factors. First, vowels can be read by themselves, as they can form a syllable, which is never the case for consonants. Second, in French, unlike English, the name of almost every vowel is the same as its sound (grapheme phoneme correspondences; Peereman et al., 2013; Peereman \& Sprenger-Charolles, 2018).

More generally, another negative factor for speech perception (and therefore for learning to read) should be added to better understand the difficulty of using lip reading: the noisy environment in which it takes place (Calcus, Hoonhorst, Colin, Deltenre \& Kolinsky, 2018). The amount of background noise in classrooms impacts typically developing children's academic performances (Bradley \& Sato, 2008). And learning to read is especially challenging for children with poor phonemic discrimination skills (Piquard-Kipffer \& Sprenger-Charolles, 2013; Snowling, Gooch, McArthur, \& Hulme, 2018). Therefore, the current situation, in which learning to read begins with teachers wearing masks, should have a negative impact on the reading skills of all children, all the stronger among those with poor phonemic discrimination skills.

\section{REFERENCES}

Alegría, J., Charlier, B. L., \& Mattys, S. (1999). The role of lip-reading and cued speech in the processing of phonological information in French-educated deaf children. European Journal of Cognitive Psychology, 11, 451-472.

Arnold, P., \& Köpsel, A. (1996). Lipreading, reading and memory of hearing and hearing- impaired children. Scandinavian Audiology, 25, 13-20. 
Bara, F., Colé P. \& Gentaz, E. (2008). Litéracie précoce et apprentissage de la lecture : comparaison entre des enfants à risque, scolarisés en France dans des réseaux d'éducation prioritaire et des enfants de classes régulières. Revue des Sciences de l'Education, 34, 27-45

Bernstein L.E. , \& Liebenthal E. (2014). Neural pathways for visual speech perception. Frontiers in Neuroscience. doi.org/10.3389/fnins.2014.00386.

Bourguignon, M., Baart, M., Kapnoula, E. \& Molinaro, N. (2020). Lip-reading enables the brain to synthesize auditory_features of unknown silent speech. The Journal of Neuroscience, 40, 1053-1065.

Bradley. J. \& Sato, H. (2008). The intelligibility of speech in elementary school classrooms. The Journal of the Acoustical Society of America, 123, 2078-2086.

Burnham D. \& Dodd B. (2004). Auditory-visual speech integration by prelinguistic infants: Perception of an emergent consonant in the McGurk effect. Developmental Psychobiology, 45, 204-220.

Calcus A., Hoonhorst I., Colin C., Deltenre \& Kolinsky R. (2018). The rowdy classroom problem in children with Dyslexia: A review. Perspectives from cognitive Neuosciences, Linguistics, Psychology and Education. In T. Lachman, T Weis (Eds), Reading and Dyslexia, Literacy Studies 16.

Casalis, S., \& Louis-Alexandre, M. (2000). Morphological analysis and learning to read in French: a longitudinal study. Reading and Writing: An Interdisciplinary Journal, 12, 303-335.

Casthe, E., Rastle, K, \& Nation, K. (2018). Endind the reading wars: Readins acquisition from novice to expert. Psychological Science in the Public Interest, 19, 5-51.

Colé, P. \& Sprenger-Charolles, (2021). La dyslexie : de l'enfant à l'adule. Paris : Dunod. 
Colin, C. \& Radeau, M. (2003). Les illusions McGurk dans la parole : 25 ans de recherches. L'Année Psychologique, 3, 497-542.

Deltour, J. J., \& Hupkens, D. (1980). Test de vocabulaire actif et passif pour enfants (5 à 8 ans). Issy-les-Moulineaux : EAP.

Desjardins, R. N., Rogers, J. \& Werker, J. F. (1997). An exploration of why preschoolers perform differently than do adults in audiovisual speech perception tasks. Journal of Experimental Child Psychology, 66, 85-110.

Dodd, B., McIntosh, B., Erdener, D. \& Burnham, D. (2008) Perception of the auditory-visual illusion in speech perception by children with phonological disorders. Clinical Phonetics and Linguistics, 22, 69-81.

Dodd, B., \& Campbell, R. (1987). Hearing by eye: The psychology of lip-reading. Lawrence Erlbaum Associates.

Erdener, D. \& Burnham, D. (2017).Auditory-visual speech perception in three- and four year-olds and its relationship to perceptual attunement and receptive vocabulary. Journal of Child Langage, 1-15.

Gentaz, E., Sprenger-Charolles, L., Theurel, A. \& Colé, P. (2013). Reading comprehension in a large cohort of French first graders from low socio-economic status families: A 7-month longitudinal study. PLoS ONE, 8(11):e78608.

Harris, M., \& Moreno, C. (2006). Speech reading and learning to read: A comparison of 8- yearold profoundly deaf children with good and poor reading ability. Journal of Deaf Studies \& Deaf Education, 11, 189-201. 
Kyle, F. E, Campbell, R., Mohammed, T., Coleman, M., \& MacSweeney, M. (2013). Speechreading development in deaf and hearing children: Introducing the Test of Child Speech reading. Journal of Speech, Language, \& Hearing Research, 56, 416-426.

Kyle, F. E., \& Harris, M. (2006). Concurrent correlates and predictors of reading and spelling achievement in deaf and hearing school children. Journal of Deaf Studies \& Deaf Education, 11, 273-288.

Liberman, A. M., \& Mattingly, I. G. (1985). The motor theory of speech perception revised. Cognition, 21, 1-36.

Mc Gurk, H., \& Mc Donald, J. (1976). Hearing lips and seeing voices. Nature, 264, 746-748.

Munhall, K. G., \& Vatikiotis-bateson, E. (1998). The moving face during speech communication. In R. Campbell, B. Dodd \& D. Burnham (Eds.), Hearing by Eye II: Advances in the psychology of speechreading and audiovisual speech. Hove: Psychology Press, 123-139.

Peereman, R., \& Sprenger-Charolles, L. (2018). Manulex-MorphO, une base de données sur l'orthographe du français intégrant les morpho-phonogrammes. Langue Française, 199, 99-109.

Peereman, R., Sprenger-Charolles, L., Messaoud-Galusi, S. (2013). The contribution of morphology to the consistency of spelling-to-sound relations: A quantitative analysis based on French elementary school readers. L'Année Psychologique/Topics in Cognitive Psychology, 113, 3-33.

Piquard-Kipffer A., \& Sprenger-Charolles L. (2013). Early predictors of future reading skills: A follow of French-speaking children from the beginning of kindergarten to the end of the second grade (age 5 to 8). L'Année psychologique/Topics in Cognitive Psychology, 113, 491-521. 
Pulvermüller F., Huss M., Kherif F., del Prado, Martin F., Hauk O., Shtyrov Y. (2006). Motor cortex maps articulatory features of speech sounds. PNAS, 20, 7865-7870.

Raven, J. C. (1981). Progressive Matrices Couleur. Issy-les-Moulineaux : EAP.

Savigny, M. (1974). BAT-ELEM. Issy-les- Moulineaux : EAP.

Sekiyama K. \& Burnham D. (2008). Impact of language on development of auditory-visual speech perception. Developmental Science, 11, 306-20.

Share, D. L. (1995). Phonological recoding and self-teaching: Sine qua non of reading acquisition. Cognition, 55, 151-218.

Snowling, M., Gooch, D., McArthur, G. \& , \& Hulme, C. (2018). Language skills, but not frequency discrimination, predict reading skills in children at risk of dyslexia. Psychological Science, 29, $1270-1282$

Sprenger-Charolles, L., Desrochers A., \& Gentaz É. (2018), Apprendre à lire-écrire en français, Langue Française, 199, 51-67.

Studdert-Kennedy, M. (2005). How did langage do discrete. In M. Tallerman (Ed), Langage Origins. Perspectives on Evolution. Oxford: Oxford University Press, 48-77.

Sumby, W. H., \& Pollack, I. (1954). Visual contribution to speech intelligibility in noise. The Journal of the Acoustical Society of America, 26, 212-215. 
Vatikiotis-Bateson, E., Eigsti, I. M., Yano, S. \& Munhall, K. G. (1998). Eye movement of perceivers during audiovisual speech perception. Perception \& Psychophysics, 60, 926940.

Viviani P. (2002). Motor competence in the perception of dynamic events: a tutorial, in W. Prinz. \& B. Hommel (eds.), Attention and performance XIX: Common mechanisms in perception and action. NY: Oxford University Press, pp. 406-442.

Ziegler, J., Perry, C., \& Zorzi, M. (2014). Modelling reading development through phonological decoding and self-teaching: Implications for dyslexia. Philosophical Transactions of the Royal Society B: Biological Sciences, 369(1634), 20120397 


\section{ACKNOWLEDGEMENTS}

We would like to thank the Meurthe et Moselle medical team of the "Protection Maternelle Infantile (PMI)" and health promotion services for Pupils of the "Service de promotion de la santé en faveur des élèves de l'Académie de Nancy-Metz, DSDEN de Meurthe et Moselle", subregional branch of the Education Ministry in Meurthe et Moselle. 
Table 1. Characteristics of the groups defined at age 5 (Time 1a) based on the scores in a phonemic discrimination test: At-risk (scores in the first quartile, $\mathrm{N}=39,24$ boys); Not-at-risk (scores above the median, $\mathrm{N}=46,28$ boys) groups

At-risk Not-at-risk

Group Group Cohen's d

$\begin{array}{lll}\text { Chronological Age (Months) } \quad 64.95(03.35) & 63.78(03.21)\end{array}$

Nonverbal IQ: Raw scores

(Raven/36)

$17.77(03.07)$

$18.83(03.56)$

Vocabulary level: Raw scores

$\begin{array}{lll}(\mathrm{TVAP} / 60) & 39.44(04.13) & 39.48(05.55)\end{array}$

\begin{tabular}{llll}
\hline Bat-Elem (Pre-reading level, \%) & $* * 50.77(19.92)$ & $63.04(17.87)$ & 0.65
\end{tabular}

Phoneme discrimination (above

chance, i.e. $50 \%$ )

$* * 06.34(06.71)$

$35.33(06.30)$

4.45 
Table 2. Comparison of mean scores on the syllabic counting test (/10) with and without the opportunity to rely on lip-reading of at-risk $(n=39)$ and not-at-risk $(n=46)$ children at ages 5 and 7 , reporting effect sizes (Cohen's D) when the difference between the conditions was significant

\section{Without lip-}

With lip-reading

reading Cohen's D

At-risk group $(n=39)$

Syllabic counting test at age 5

6.949 (2.772)

$6.128(3.469)$

Syllabic counting test at age 7

*7.00 (2.743)

$6.128(3.172) \quad 0.380$

Not-at-risk group $(n=46)$

Syllabic counting test at age 5

7.978 (2.324)

7.913 (2.589)

Syllabic counting test at age 7

*9.348 (1.197)

8.978 (1.483) 0.371

$* p=<.05$ 
Figure 1a and b. Mean syllabic counting scores (with error bars) as a function of age (5 and 7) and lip-reading (without or with) conditions for the at-risk group (on the left; Fig.1a) and the notat-risk group (on the right; Fig. 1b)
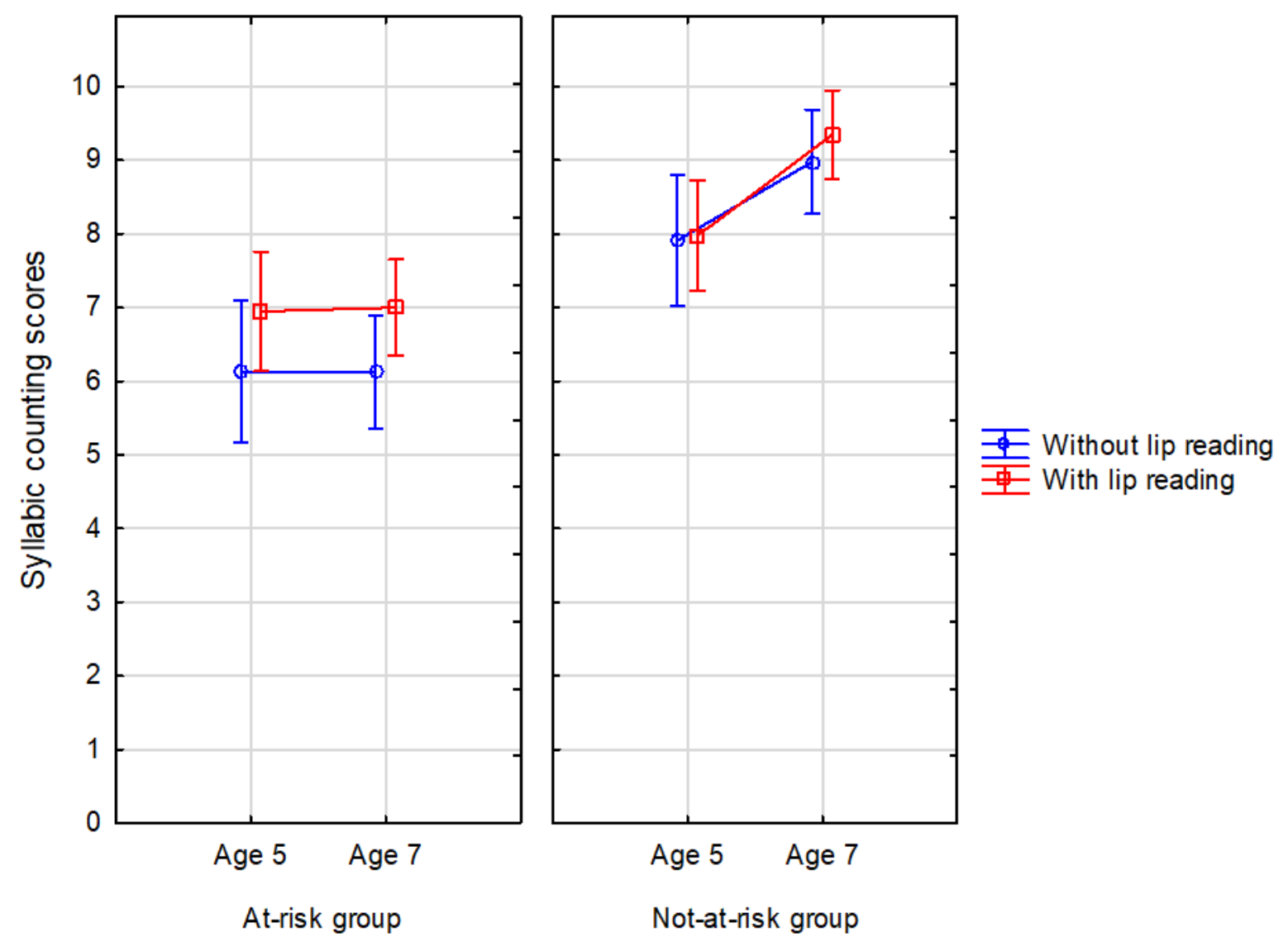